\title{
Stress Analysis of a Rotating Body by Means of Photostress Method and Using Solidworks Programme
}

\author{
Ján Kostka*, Peter Frankovský, František Trebuňa, Miroslav Pástor, František Šimčák \\ Technical University of Košice, Faculty of Mechanical Engineering, Košice, Slovakia \\ *Corresponding author: jan.kostka@tuke.sk
}

Received September 02, 2014; Revised September 17, 2014; Accepted October 17, 2014

\begin{abstract}
The paper is dedicated to the examination of stress states of a rotating body which occur due to centrifugal forces. In order to determine stress and stain distribution, photoelastic PhotoStress method was applied and a measurement device - polariscope LF/Z-2 was used. The sample under examination was subjected to loads of various magnitudes and, subsequently, recorded with a photographic device. For objective evaluation of detected results, the object under examination was modelled and simulated in programme SolidWorks 2012.
\end{abstract}

Keywords: photostress method, dynamic stress analysis, photoelasticity, isochromatic lines, solidworks

Cite This Article: Ján Kostka, Peter Frankovský, František Trebuňa, Miroslav Pástor, and František Šimčák, "Stress Analysis of a Rotating Body by Means of Photostress Method and Using Solidworks Programme." American Journal of Mechanical Engineering, vol. 2, no. 7 (2014): 226-230. doi: 10.12691/ajme-2-7-11.

\section{Introduction}

When carrying out a dynamic stress analysis, it is vital to be familiar with certain physical phenomena which occur in objects under examination. A body, in our case a body which is rotating around its fixed axis, has certain kinetic energy. It can be determined without any attempt to calculate performance which is necessary to put the body in rotating motion, i.e. directly through integration of kinetic energy values of individual material elements.

Kinetic energy of a material element can be examined via calculations of kinetic energy of a material point:

$$
d E_{k}=\frac{1}{2} d m v^{2}
$$

where: $d E_{k}$ - kinetic energy of the element,

$d m$ - mass of the element under examination,

v- velocity of the element under examination.

Since velocities of individual material elements of the body are not identical, total kinetic energy of the rotating body under examination equals the sum of kinetic energy values of all individual elements of the body, i.e.:

$$
E_{k}=\int \frac{1}{2} d m v^{2}
$$

The following applies to the velocity of an individual element of the body under examination:

$$
v=\omega r,
$$

where: $\omega$ - angular velocity of the rotating body,

$r$ - distance of the relevant body from rotation axis.

Then, substituting for $v$ we obtain:

$$
E_{k}=\int \frac{1}{2} \omega^{2} r^{2} d m
$$

Angular velocity $\omega$ is in given moment identical for all elements of the body, hence it can be placed before integral resulting in:

$$
E_{k}=\frac{1}{2} I \omega^{2}
$$

where I (body moment of inertia) represents:

$$
I=\int r^{2} d m \text {. }
$$

The rotating body is loaded by centrifugal forces having the nature of body forces. Stresses which occur during rotation are symmetrical with respect to rotation axis, hence can be expressed as a function of distance $r$ from the rotation axis. Stresses in the rotating body of constant thickness $h$ are evenly distributed along whole thickness of the rotating body, and stress $\sigma_{z}$ equals zero in the direction of $z$-axis. Centrifugal force is defined as:

$$
d F_{o}=d m \omega^{2} r=\rho h r d \varphi d r \omega^{2} r,
$$

where: $d \varphi$ - angle delimiting the element of the rotating body,

$\rho$ - specific mass of the material of the rotating body,

$h$ - thickness of the material $[5,6]$.

\section{Photoelasticity}

Photoelasticity is an experimental method which enables determination of deformations and stress states in a body. Measurement device which is used for the examination by means of this experimental method is 
known as polariscope. It is based on polarisation and temporary birefringence of a light beam. Temporary light birefringence occurs, provided that an optically isotropic material exhibits anisotropic characteristics after loading. To be more specific, the above-stated means that in the examined model there is a decomposition of one bean into two beams which vectors oscillate in different planes though perpendicularly to each other. These planes determine directions of principal stresses, and beams which oscillate in these planes are being distributed throughout the model under examination with a different speed due to the state of anisotropy. Phase shift occurs as a result of differences of the speed of individual beams. Phase shift has crucial influence on stress-state examination of the bodies [1].

\subsection{Reflection Photoelasticity - PhotoStress}

PhotoStress method represents reflection photoelasticity which is a technique of stress determination in structures, systems or components. It is as well applied when measuring surface deformations during dynamic load. It belongs to experimental methods and its principle has not considerably changed since the beginning of 1950's, although measurements are taken with rather advanced polariscopes.

A strain-optical layer is applied to the surface of the component which undergoes the measurement. When illuminated with polarised light and viewed through the polariscope, the coating on the component surface is seen as decomposition of strains in form of a colourful spectrum. These colourful patterns are known as isochromatic lines (isochromatics). These represent geometrical locations of points in which the difference of principal strains is constant, and immediately point at different magnitudes of strains with areas of maximum strains. The stress analysis can be performed thanks to an optical compensator attached to the polariscope. A video camera or a digital camera can be attached to the measurement device - the polariscope to record different values of loads $[2,4]$.

\section{Experimental Analysis of the Rotating Body}

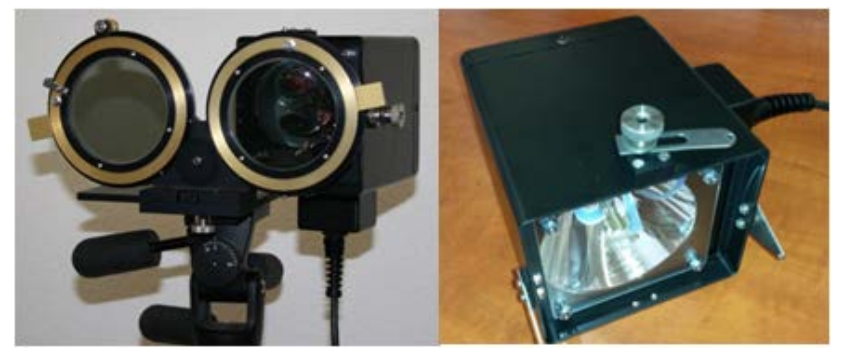

Figure 1. Reflection polariscope LF/Z-2 and stroboscopic light

The principle of PhotoStress method within the solution of dynamic effects lies in the scanning of phenomena which reoccur periodically during the same period of time. When examining the rotating structural element with photoelastic coating, the element under consideration is being illuminated for a short period of time and always in the same position in order to depict a static picture of isochromatic lines. During circular movement of the component under consideration an impression of a static picture arises due to the source of stroboscopic light. Figure 1 depicts polariscope LF/Z-2 and stroboscopic light used in PhotoStress method [6].

The proposed sample with diameter $150 \mathrm{~mm}$ and a centre hole with diameter $5 \mathrm{~mm}$ was drawn in programme SolidWorks 2012. The sample was later attached to the rotating shaft through the centre hole with a nut. After drawing and after being stored in DWG format, the file was sent for cutting into a photoelastic material. Figure 2 depicts a drawing of the sample under examination with required size.

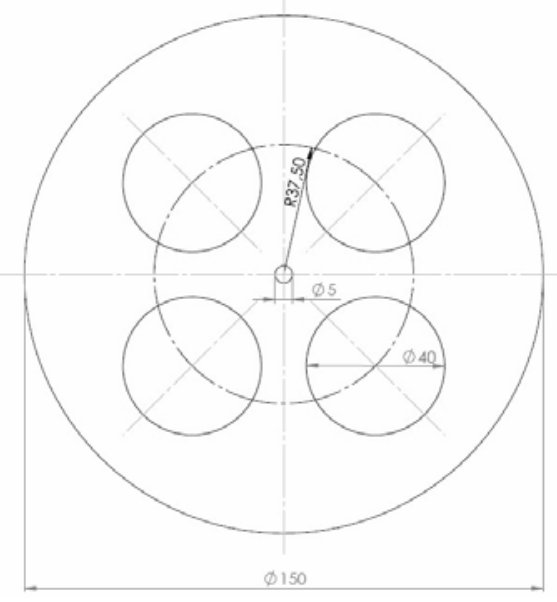

Figure 2. Drawing of the sample for experimental dynamic analysis

\subsection{Material and Division of the Sample under Analysis}

Right selection of material is an important criterion of rotating bodies in order to prevent its destruction at higher speeds. In our case, it was a photoelastic material PS-1 which was subjected to measurements. These measurements were transferred into initial solid plane plates after simulation drawing in programme SolidWorks and water-jet cutting. For the purposes of the experiment, the material PS-1 had been produced and delivered by American company Vishay Photoelastic Division of Measurements Group, Inc. The material exhibits high sensitivity and can be used in an elastic as well as an elastic-plastic area. Is is delivered together with a reflection layer and a protective temporary paper package. Listed in Tab. 1 are material characteristics of photoelastic material PS-1 [5].

Table 1. Material characteristics of photoelastic material PS-1

\begin{tabular}{|c|c|}
\hline Strain-optical constant K (-) & 0,150 \\
\hline Modulus of elasticity E (GPa) & 2,5 \\
\hline Ductility (\%) & 5 \\
\hline Poisson's ratio $\mu(-)$ & 0,38 \\
\hline Thickness $(\mathrm{mm})$ & 3,05 \\
\hline Tolerance $(\mathrm{mm})$ & $\pm 0,06$ \\
\hline Sensitivity constant $\left({ }^{\circ} \mathrm{C}\right)$ & 150 \\
\hline Maximum temperature $\left({ }^{\circ} \mathrm{C}\right)$ & 150 \\
\hline Maximum elongation $(\%)$ & 3 \\
\hline
\end{tabular}

For verification of some material characteristics the solid plane plate PS-1 was subjected to load in point as shown in Figure 3. The plate was then viewed through reflection polariscope LF/Z-2. 


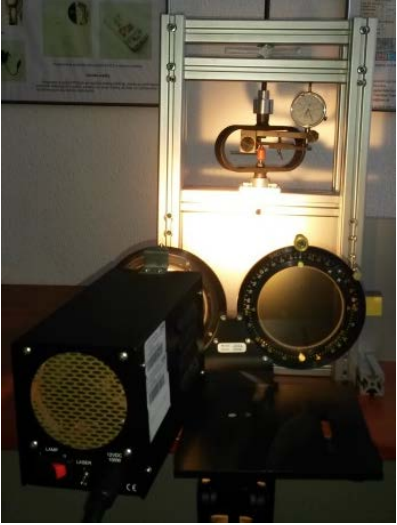

Figure 3. Verification of material characteristics of PS-1

In order to measure and evaluate the object under examination and analysis objectively, it is very important to choose the most proper way of sample material separation. In our case, with the measured object made of a photoelastic material, we had to eliminate heat effect or residual stresses in the cutting area. The best and the easiest option was to separate the material with water jet. The sample under examination was carved out by Watting, s.r.o. with its seat in Prešov. The separation was done with the device type AquaCut 3001.20Wr.

\subsection{Measurement Chain}

The measurement chain, after set-up, included (position number in Figure 4): reflection polariscope LF/Z-2 (1),stroboscopic white light STROBEX Model 135M-11 (2), digital camera attachment (3), power supply (4), structure frame to attach the motor (5), signal generator (6), motor HSM 60 (7), photoelastic object to be examined (8), digital camera and portable computer. For determination of velocity of the rotating samples we used digital laser revolution counter Laser Tacho.

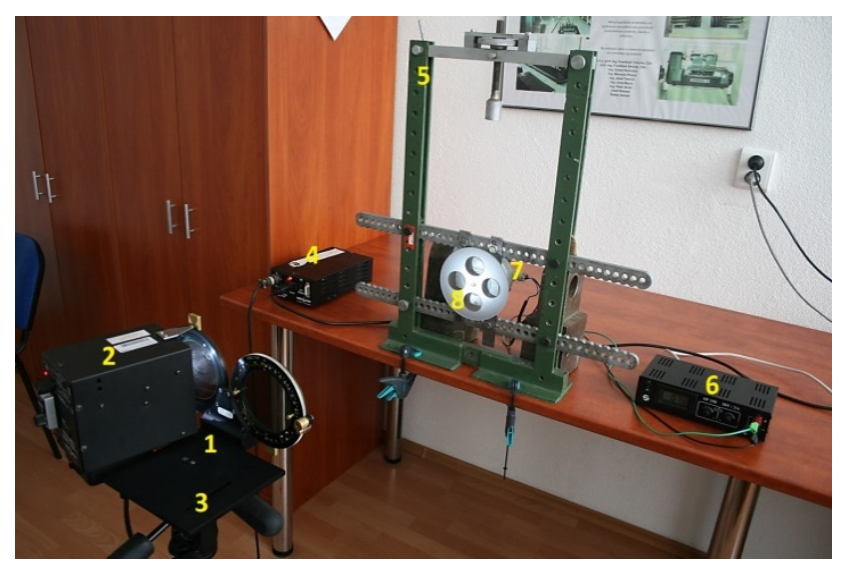

Figure 4. Measurement chain in dynamic stress analysis

\subsection{Analysis of Isochromatic Fringes}

When analysing isochromatic fringes, the polariscope LF/Z-2 was set to the position "MAGNITUGE". The laboratory was partially dimmed for better recording of colourful isochromatic lines. The rotating body under consideration was attached to the motor and, as revolutions were increasing in a clockwise direction, the body of a constant thickness was continually loaded by centrifugal forces. At very low revolutions of the body no change of colourful lines occurred on the surface of the element under examination, i.e. the colour shade was grey as when the material PS-1 was not loaded. Colourful lines appeared with continuous increase of motor revolutions. These lines reoccurred when the whole colour spectrum was displayed. Black areas represented zero-stress areas. With every increase of rotational speed new pictures of the rotating model were taken. The examined components were not loaded to maximum capacity as there was a high risk of destruction, material breakdown and endangerment of persons carrying out the measurement. Figure 5 shows pictures of isochromatic lines (fringes) at continuous increase of revolutions of the light-weight disc during examination [2].

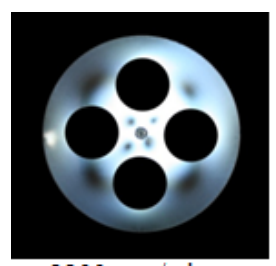

$2200 \mathrm{rev} . \mathrm{min}$.

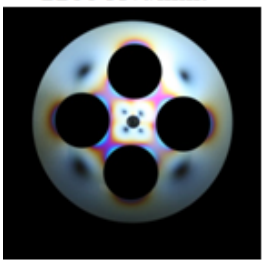

$3400 \mathrm{rev} . / \mathrm{min}$.

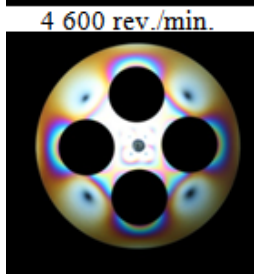

$5800 \mathrm{rev} . / \mathrm{min}$

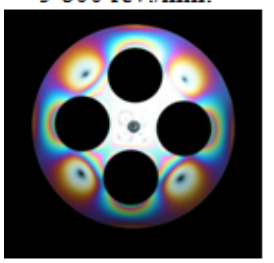

$7000 \mathrm{rev} . / \mathrm{min}$

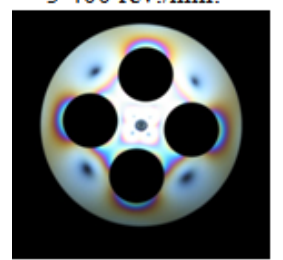

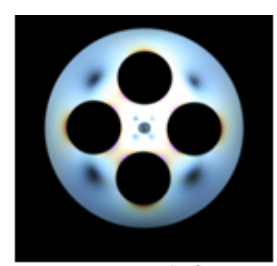

$2600 \mathrm{rev} . \mathrm{min}$.

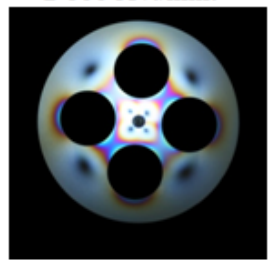

$3800 \mathrm{rev} . \mathrm{min}$.
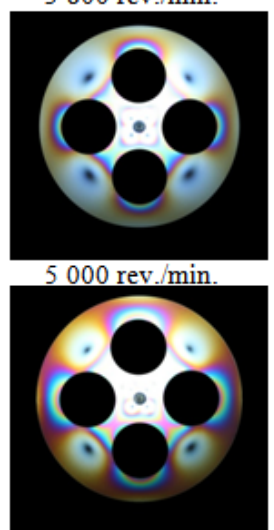

$6200 \mathrm{rev} . \mathrm{min}$.

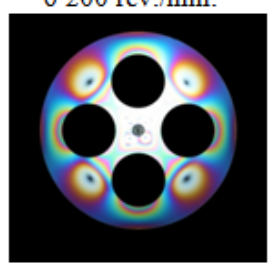

$7400 \mathrm{rev} . \mathrm{min}$

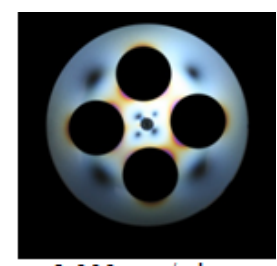

$3000 \mathrm{rev} . / \mathrm{min}$.

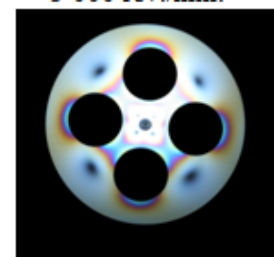

$4200 \mathrm{rev} . \mathrm{min}$
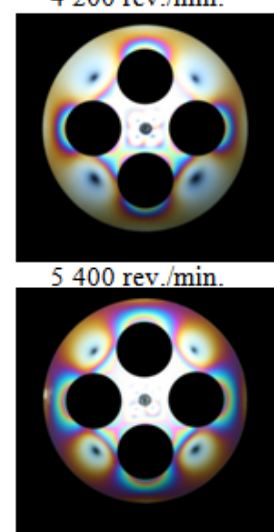

$6600 \mathrm{rev} . \mathrm{min}$

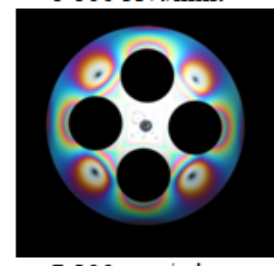

$7800 \mathrm{rev} . / \mathrm{min}$
Figure 5. Isochromatic lines during continuous increase of rotations of the rotating body model under examination

Considering the pictures of the model, it is obvious that the most loaded parts were the narrowest parts of the component. In these so called critical areas, colourful patterns started to reoccur when gradually increasing the revolutions, while some fringes disappeared completely.

\section{Evaluation and Comparison of Results}

For more objective analysis and evaluation of the model, the object was modelled in programme SolidWorks 2012. 
Object simulation was launched after input parameters and maximum speed of $7800 \mathrm{rev} . / \mathrm{min}$. were set - this maximum speed was set for the model rotating in clockwise direction - and model network had been created. After all calculations were completed, the model was depicted with all stresses, displacements and strains. Eight points were selected on the surface of the model which lead from the attachment centre to the edge of the model in order to recognise precise values. Differences of principal normal stresses, which were determined for the half of the object surface, were depicted in the programme as shown in Figure 6.

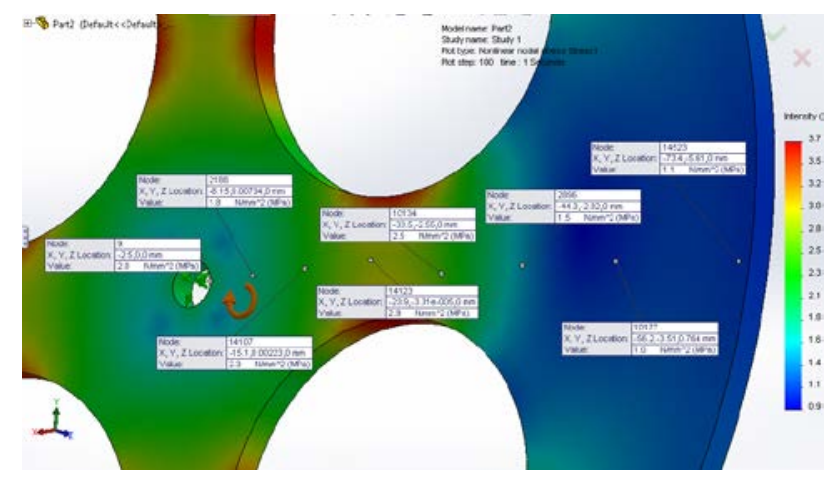

Figure 6. Differences of principal normal stresses along the half of the model

In the following step, a stress intensity diagram was created in which the behaviour of differences of principal normal stresses can clearly be identified. Whole sample was presented for better imagination of the abovementioned processes (Figure 7). The sample is symmetrical, i.e. it is enough to take into consideration only one half of the model.
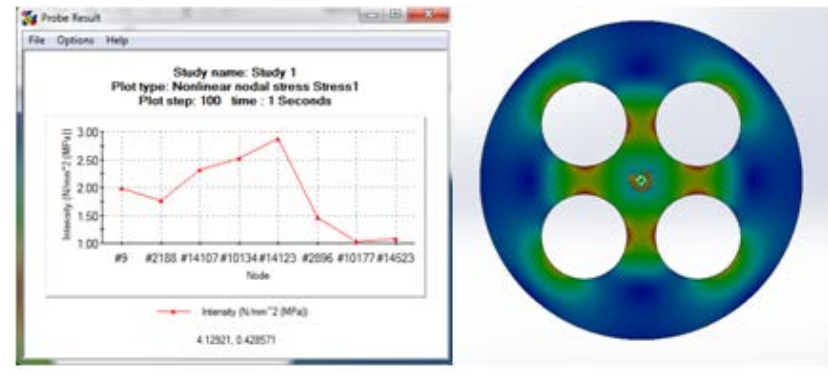

Figure 7. Stress intensity diagram and the model of whole rotating sample under examination

Closest to the centre hole the stress intensity equals 2 $\mathrm{MPa}$. Later, it dropped to $1,8 \mathrm{MPa}$ as a result of stress decomposition on a bigger surface, and started gradually increasing again up to node 14123 where it reached its maximum value of 2,9 $\mathrm{MPa}$. The given area can be considered critical. From this node the intensity started decreasing to $1 \mathrm{MPa}$, and at the end of the analysed model it slightly rose to $1,1 \mathrm{MPa}$.

In the most critical part of the model subject to examination, where stress intensity equals 2,9 $\mathrm{MPa}$, stress intensity values were identified by means of "probe" function, i.e. along the edges of holes cut into the lightweight parts of the model as shown in Figure 8.

Differences of principal normal stresses showed identical values of 3,7 MPa. Considering the abovementioned, it can be concluded that the direction of model rotation (clockwise or anti-clockwise rotation), or in our case rotation of the sample examined by means of PhotoStress method at comparable speed of 7800 rev./min., is of no importance.

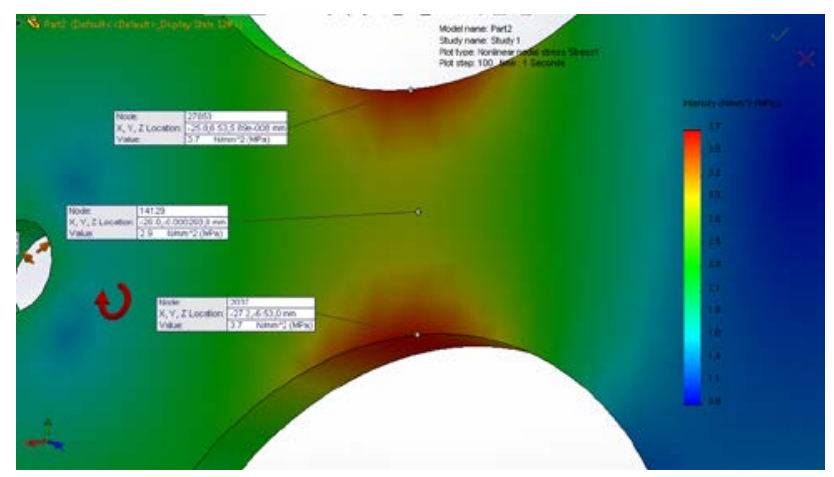

Figure 8. Differences of principal normal stresses in the narrowest area of the rotating disc model

\section{Conclusion}

In the experimental stress analysis and via subsequent verification by means of the finite element method carried out on the rotating body under consideration of centrifugal forces the most critical areas of the sample (model) were identified. These areas were the narrowest parts of the component subject to examination. Though not reported in this paper, there were other experimental examinations of a variety of other samples to identify stress distributions. These were radically changing due to different cut openings in the component. Not all forms of weight reduction were appropriate for the implementation into practical areas, since requirements of engineering and industry practice may be immensely challenging. Subsequently, the simulation was used as a verification tool to identify if graphical representations of stress distributions on the components were correct. The results of the analyses may have slightly varied due to potential inaccuracy of measurements, air humidity, temperature during measurement in the laboratory conditions or unstable network voltage, though it is relevant to sum up that this method of dynamic photoelasticity, which is newly implemented at the Department of Applied Mechanics and Mechatronics of the Faculty of Mechanical Engineering of the Technical university in Košice has a great future potential in the analysis of structural elements under consideration of centrifugal force effects.

\section{Acknowledgement}

This work was supported by projects VEGA 1/0937/12 and APVV-0091-11.

\section{References}

[1] Trebuňa, F., Šimčák, F., Príručka experimentálnej mechaniky [Handbook of experimental mechanics]. TypoPress, Košice, 2007.

[2] Trebuňa, F., Princípy, postupy, prístroje v metóde PhotoStress [Principles, procedures, devices in PhotoStress method]. TypoPress, Košice, 2006.

[3] Trebuňa, F., Jadlovský, J., Frankovský, P., Pástor, M., Automatizácia v metóde Photostress [Automation in PhotoStress method]. 1. issue. Košice: TU - 2012. 
[4] Kostka, J., Optické metódy a ich uplatnenie v priemyselnej praxi [Optical methods and their utilisation in industrial practice]. Bachelor thesis, Košice, 2012.

[5] Kostka, J.,Využitie metódy PhotoStress pri napätovej analýze konštrukčných prvkov s uvážením vplyvu odstredivých síl [Application of PhotoStress method in stress analysis of structural elements under consideration of centrifugal force effect]. Diploma thesis, Košice, 2014.
[6] Frankovský, P., Trebuňa, F., Application of photostress method in stress analysis of a rotating disc. Metalurgija 53.4 (2014): 541-544.

[7] Kobayashi, A. S.,Handbook on Experimental Mechanics. Society for Experimental Mechanics, Seattle, 1993.

[8] Trebuňa, F., Jadlovský, J., Frankovský, P., Bakšiová, Z., Kostelníková, A., Further Possibilities of Using Software PhotoStress for Separation of Principal Normal Stresses. Acta Mechanica,Slovakia. 